\title{
Note
}

\section{The Effect of Combined Treatment with Carbonation, Heating, and Monoglycerol Fatty Acid Esters on the Inactivation and Growth Inhibition of Geobacillus stearothermophilus Spores}

\author{
Tomoe NAKaI ${ }^{1}$, Saburo Tani ${ }^{2}$, Wannaporn KlangPetch ${ }^{1}$, Seiji Noma ${ }^{* 3}$, Noriyuki Igura ${ }^{3}$ and Mitsuya Shimoda ${ }^{3}$ \\ ${ }^{1}$ Graduate School of Bioresource and Bioenvironmental Sciences, Kyushu University, 6-10-1 Hakozaki, Higashi-ku, Fukuoka 812- \\ 8581, Japan \\ ${ }^{2}$ Faculty of Agriculture, Kyushu University, 6-10-1 Hakozaki, Higashi-ku, Fukuoka 812-8581, Japan \\ ${ }^{3}$ Division of Food Science \& Biotechnology, Department of Bioscience \& Biotechnology, Kyushu University, 6-10-1 Hakozaki, \\ Higashi-ku, Fukuoka 812-8581, Japan
}

Received September 12, 2013 ; Accepted December 1, 2013

The effect of carbonation with heating (CH) on the number of viable Geobacillus stearothermophilus spores was investigated in the presence of monoglycerol-caprate $\left(\mathrm{MC}_{10}\right)$ or -laurate $\left(\mathrm{MC}_{12}\right)$. $\mathrm{CH}$ was performed at 90 and $100^{\circ} \mathrm{C}, 5 \mathrm{MPa}$, for 30 or $60 \mathrm{~min}$. Spore counts were reduced by $1.4 \log \mathrm{CFU} / \mathrm{ml}$ after $\mathrm{CH}$ at $90^{\circ} \mathrm{C}$ for $60 \mathrm{~min}$ in the presence of $\mathrm{MC}_{10}$. On the other hand, after $\mathrm{CH}$ at $100^{\circ} \mathrm{C}$ for $60 \mathrm{~min}$, spore counts decreased by $3-4 \log \mathrm{CFU} / \mathrm{mL} \mathrm{or}$ remained low after 7 days of storage. $\mathrm{CH}$ decreased the optical density of a spore suspension at $650 \mathrm{~nm}$ more than heat treatment alone, indicating that spore germination triggered by $\mathrm{CH}$ could be involved in the drastic decrease in spore count caused by $\mathrm{CH}$ in the presence of $\mathrm{MC}_{10}$ or $\mathrm{MC}_{12}$.

Keywords; carbonation, monoglycerol fatty acid ester, G. stearothermophilus spore

\section{Introduction}

Carbonation treatment is performed by solubilizing carbon dioxide $\left(\mathrm{CO}_{2}\right)$ into liquid foods under pressure. This is one of the most promising techniques for cold pasteurization and/or sterilization of liquid and solid materials, and is likely to replace or partially substitute currently and widely applied thermal processes (Spilimbergo and Bertucco, 2003). Over the past decades, many reports have demonstrated the substantial inactivation effect of carbonation under mild treatment conditions against various microorganisms in vegetative form, such as Escherichia coli (Dillow et al., 1999), Listeria monocytogenes (Wei et al., 1991), and Lactobacillus plantarum (Hong and Pyun., 1999). However, spores of various Bacillus species are metabolically dormant and are thus highly resistant to environmental stress factors (Ghosh et al., 2008). Therefore, it is difficult to inactivate spores by carbonation treatment alone without deteriorating the quality of the food.

Fatty acid esters (FAEs), which are used widely as food additives, are known to effectively inhibit the growth of various bacteria both in vegetative and spore forms (Shibasaki, 1979). Medium chain length monoglycerol FAEs, and especially monolaurin, show an antibacterial effect against bacterial spores (Kimsey et al., 1981). We previously demonstrated that the presence of monoglycerol monocaprate $\left(\mathrm{MC}_{10}\right)$ and monoglycerol monolaurate $\left(\mathrm{MC}_{12}\right)$ substantially decreased the viable counts of $B$. subtilis spores after carbonation with heating $(\mathrm{CH})\left(80^{\circ} \mathrm{C}, 5 \mathrm{MPa}\right.$, $30 \mathrm{~min}$ ) and prevented their growth during 30 days of storage (Klangpetch et al., 2013). We also revealed the significant inactivation effect of combined treatment of $\mathrm{CH}$ with $\mathrm{MC}_{10}$ or $\mathrm{MC}_{12}$ on B. cereus and B. coagulans. In contrast, Geobacillus 
stearothermophilus spores were not affected by combined treatment with $\mathrm{CH}\left(80^{\circ} \mathrm{C}, 5 \mathrm{MPa}, 30 \mathrm{~min}\right)$ and $\mathrm{MC}_{10}$ or $\mathrm{MC}_{12}$. The fact that $G$. stearothermophilus is known as one of the most heat resistant spores amongst aerobic microorganisms suggested that these conditions for heat treatment during $\mathrm{CH}$ were insufficient to substantially inactivate highly heat resistant spores. In this study, the combined effects of $\mathrm{CH}$ with $\mathrm{MC}_{10}$ or $\mathrm{MC}_{12}$ on $G$. stearothermophilus spores at higher temperatures $\left(90\right.$ and $\left.100^{\circ} \mathrm{C}\right)$ and for longer times (30 and $60 \mathrm{~min}$ ) were studied.

\section{Materials and Methods}

Preparation of FAE solution The two types of $\mathrm{FAE}, \mathrm{MC}_{10}$ and $\mathrm{MC}_{12}$, were kindly provided by Taiyo Kagaku Co. (Mie, Japan). Their average molecular weights are 246 and 274, and their hydrophile/lipophile balances are 6.5 and 5.3, respectively. They were dissolved in sterile water to a concentration of $0.5 \%(\mathrm{w} / \mathrm{v})$.

Bacteria and preparation of spore suspension Geobacillus stearothermophilus JCM 2501 was obtained from RIKEN BRCJCM (Saitama, Japan). The spores were formed on nutrient agar (NA; Difco Inc., Detroit, USA) containing $0.1 \mathrm{mM} \mathrm{MnSO}_{4}$ at $55^{\circ} \mathrm{C}$ for about 10 days. After more than $90 \%$ of the population appeared as reflective spores under phase contrast microscopy (BX 50, Olympus Co., Tokyo, Japan), the spores were harvested and washed three times by centrifugation at $7,000 \times \mathrm{g}$ at $4{ }^{\circ} \mathrm{C}$ for $10 \mathrm{~min}$ in sterile water. The spore suspension was heated at $90^{\circ} \mathrm{C}$ for $30 \mathrm{~min}$ in order to inactivate the vegetative cells, then the suspension was lyophilized and stored at $-20^{\circ} \mathrm{C}$ until use.

$\mathrm{CH}$ and heat treatment (HT) Lyophilized spores of $G$. stearothermophilus were suspended in nutrient broth (NB; Difco Inc., Detroit, USA) at an optical density of 1.5 at $650 \mathrm{~nm}$. After heating the spore suspension at $90^{\circ} \mathrm{C}$ for $30 \mathrm{~min}$, it was cooled immediately and diluted with NB to yield a final spore concentration of about $10^{5} \mathrm{CFU} / \mathrm{mL}$. The spore suspension $(2.7$ $\mathrm{mL}$ ) was mixed with $0.3 \mathrm{~mL}$ of the FAE solution described above, giving a final FAE concentration of $0.05 \%$. The $\mathrm{pH}$ of the spore suspensions was 7.0 without FAE and 6.6-6.8 with FAE. The spore suspensions with and without each FAE were subjected to $\mathrm{CH}$ and $\mathrm{HT}$.

$\mathrm{CH}$ and HT were conducted using a method similar to that reported previously (Klangpetch et al., 2013). In this study, an oil bath (OBS-200AM, AS ONE Co., Osaka, Japan) was used to control the processing temperature. $\mathrm{CH}$ was performed at 90 or $100^{\circ} \mathrm{C}$ and at a pressure of $5 \mathrm{MPa}$ for 30 or $60 \mathrm{~min}$. HT was performed under atmospheric conditions at the same temperature and for the same duration as $\mathrm{CH}$. The spore suspensions subjected to $\mathrm{CH}$ and HT were immediately cooled by immersion in icecooled water.

Determination of viable counts After $\mathrm{CH}$ or $\mathrm{HT}$, viable counts were determined as described previously (Klangpetch et al., 2013). To study the changes in spore count during storage, each spore suspension was stored at $55^{\circ} \mathrm{C}$ in sterile plastic tubes. After 1, 3, and 7 days, viable counts were enumerated.

Measurement of optical density The optical densities of the spore suspensions (about $10^{7} \mathrm{CFU} / \mathrm{mL}$ ) were measured at $650 \mathrm{~nm}$ $\left(\mathrm{OD}_{650}\right)$ using a spectrophotometer (UV-1700, Shimadzu, Kyoto, Japan) before and just after $\mathrm{CH}$ or HT to evaluate spore germination.

Statistical analysis Significant differences were determined by the Student's or Welch's $t$-test (Microsoft Excel, Microsoft Corporation, Redmond, USA) after the $f$-test to ensure the equality of variance $(p<0.01)$. Fisher's least significant difference was employed to determine statistically significant differences in $\mathrm{OD}_{650}$ among the treated samples $(p<0.05)$.

\section{Results}

Combined effect of $\mathrm{CH}$ with $M C_{10}$ or $M C_{12}$ on the viability of $G$. stearothermophilus spores Fig. 1 shows the viable counts of $G$. stearothermophilus spores after $\mathrm{CH}\left(90^{\circ} \mathrm{C}, 5 \mathrm{MPa}, 30\right.$ or $\left.60 \mathrm{~min}\right)$ with and without $\mathrm{MC}_{10}$ or $\mathrm{MC}_{12}$ at a concentration of $0.05 \%(\mathrm{w} / \mathrm{v})$. Without FAEs, spore counts were not affected by HT or CH (0-day storage) and increased by about $2 \log \mathrm{CFU} / \mathrm{mL}$ after 1 day of storage. After that, spore counts in all samples decreased to almost the same level as that on day 0 . The reason for this is not clear. One possible explanation for this decrease is that spore vegetative growth after outgrowth reached stationary phase, and a part of the culture was died. In the presence of $\mathrm{MC}_{10}$ or $\mathrm{MC}_{12}$, growth of both untreated and HT- or CH- treated spores was inhibited during 7 days of storage. Although $\mathrm{CH}$ for $60 \mathrm{~min}$ decreased spore counts by $1.4 \log \mathrm{CFU} / \mathrm{mL}$ in the presence of $\mathrm{MC}_{10}$, under the other treatment conditions, neither HT nor $\mathrm{CH}$ had any effect on spore
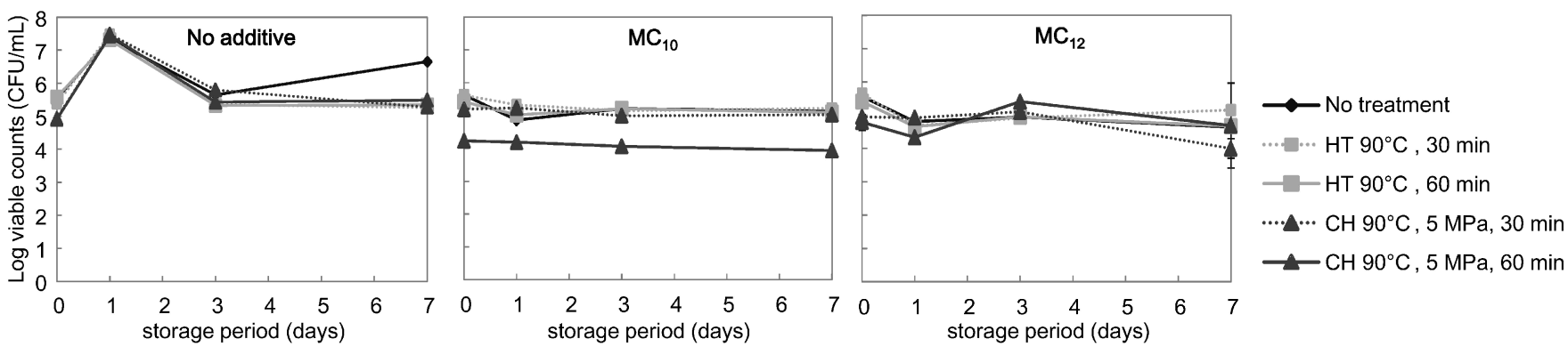

Fig. 1. Changes in viable counts of G. stearothermophilus during 7 days of storage. Spore counts at day 0 were obtained immediately following treatment. 

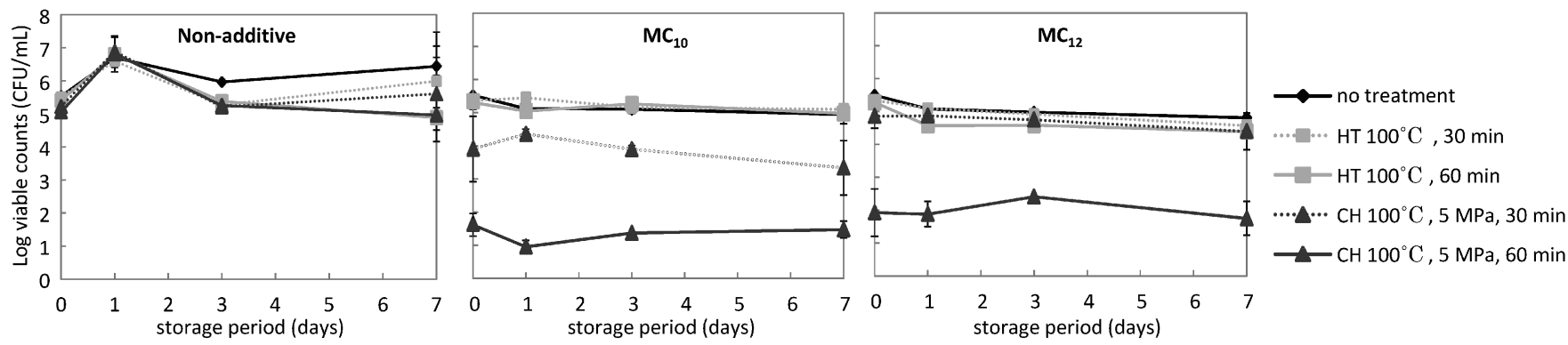

Fig. 2. Changes in viable counts of G. stearothermophilus during 7 days of storage. Spore counts at day 0 were obtained immediately following treatment.

counts. As a result, $\mathrm{CH}$ at $90^{\circ} \mathrm{C}$ did not effectively induce inactivation.

At $100^{\circ} \mathrm{C}$, spore counts were also not affected by $\mathrm{HT}$ or $\mathrm{CH}$ without $\mathrm{MC}_{10}$ or $\mathrm{MC}_{12}$ (Fig. 2). However, spore counts decreased significantly after $\mathrm{CH}$ for $60 \mathrm{~min}$ in the presence of $\mathrm{MC}_{10}$ or $\mathrm{MC}_{12}$ $(p<0.01)$, while HT caused no reduction in viable counts. In the presence of $\mathrm{MC}_{10}, \mathrm{CH}$ for 30 or 60 min induced a 1.6 and 3.9-log reduction, respectively. In the presence of $\mathrm{MC}_{12}, \mathrm{CH}$ for $60 \mathrm{~min}$ induced a $3.6-\log$ reduction, while $\mathrm{CH}$ for $30 \mathrm{~min}$ did not induce any reduction. During storage after $\mathrm{CH}$ for $60 \mathrm{~min}, \mathrm{MC}_{10}$ or $\mathrm{MC}_{12}$ inhibited spore outgrowth and/or vegetative growth, and kept spore counts below $2 \log \mathrm{CFU} / \mathrm{mL}$ during 7 days of storage.

Germination of $G$. stearothermophilus spores by $\mathrm{CH}$ Germination of G. stearothermophilus spores by $\mathrm{CH}$ or HT was investigated by measuring the $\mathrm{OD}_{650}$ of the spore suspensions (Fig. 3). The decrease in $\mathrm{OD}_{650}$ after $\mathrm{CH}\left(90^{\circ} \mathrm{C}, 60 \mathrm{~min}\right.$ and $\left.100^{\circ} \mathrm{C}, 60 \mathrm{~min}\right)$ was significantly greater than that after $\mathrm{HT}$ at the corresponding treatment temperature and time for each $\mathrm{CH}(p<0.05)$. This result indicates that $\mathrm{CH}$ induces spore germination. Additionally, increasing the $\mathrm{CH}$ temperature from 90 to $100^{\circ} \mathrm{C}$ and the treatment time from 30 to $60 \mathrm{~min}$ tended to enhance the decrease in $\mathrm{OD}_{650}$, indicating spore germination.

\section{Discussion}

In our previous study, $\mathrm{CH}\left(80^{\circ} \mathrm{C}, 5 \mathrm{MPa}, 30 \mathrm{~min}\right)$ in the presence of $\mathrm{MC}_{10}$ or $\mathrm{MC}_{12}$ decreased the number of viable spores of B. subtilis by 3.9 and $2.9 \log \mathrm{CFU} / \mathrm{mL}$, respectively, and inhibited spore outgrowth and/or vegetative growth during storage for 30 days, while $\mathrm{CH}$ or FAEs alone showed no effect on spore counts (Klangpetch et al., 2013). Monoglycerol FAEs had a more pronounced combined effect with $\mathrm{CH}$ than did di- and polyglycerol FAEs, consistent with the primary bacteriostatic effect of FAEs reported earlier (Kato and Shibasaki, 1975; Nakayama et al., 2003). A previous study also revealed greater susceptibility of $B$. cereus to $\mathrm{CH}$ and FAEs compared to B. subtilis (Klangpetch et al., 2013). The heat-resistant spores of $B$. coagulans were substantially inactivated by combined treatment with $\mathrm{CH}$ and FAEs, although the spore counts increased after 7 days of storage. In contrast with these Bacillus spores, G. stearothermophilus spores were not affected by combined treatment with $\mathrm{CH}\left(80^{\circ} \mathrm{C}, 5 \mathrm{MPa}, 30 \mathrm{~min}\right)$ and FAEs. The spore of G. stearothermophilus is the most heattolerant of all aerobic spore-forming bacteria, and is often used as a biological indicator to evaluate sterilization processes because of its high heat resistance (Furukawa et al., 2000). It has been reported that high temperature and long treatment times with $\mathrm{CH}$ were needed to cause a 5-log reduction of $G$. stearothermophilus viable spore count $\left(95^{\circ} \mathrm{C}, 30 \mathrm{MPa}, 120 \mathrm{~min}\right)$ compared to the same reduction of $B$. cereus spores $\left(50^{\circ} \mathrm{C}, 30 \mathrm{MPa}, 60 \mathrm{~min}\right.$ ) (Ishikawa et al., 1997). These results suggest that more severe treatment conditions are needed for obtaining the combined effect of $\mathrm{CH}$ and

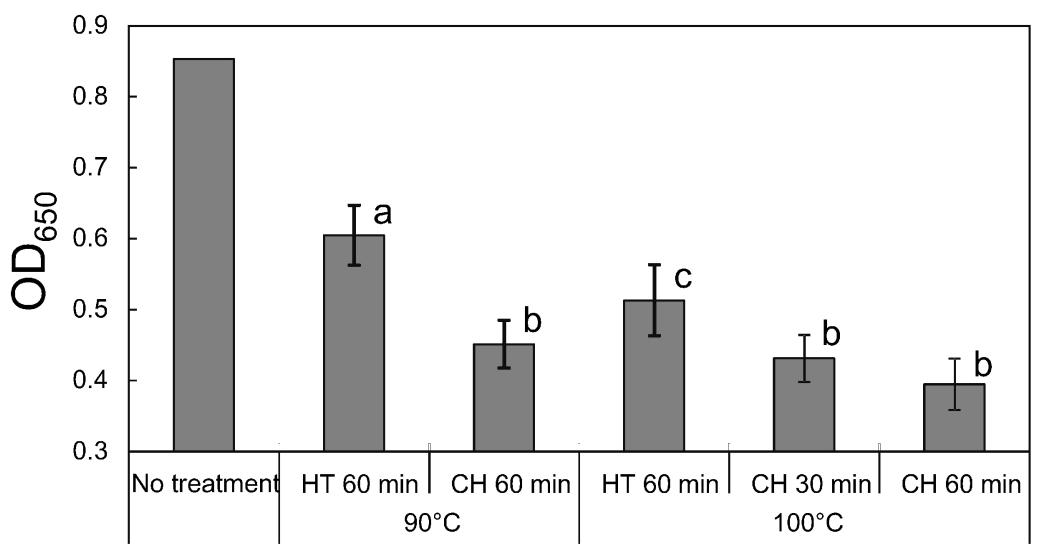

Fig. 3. Effects of $\mathrm{HT}$ and $\mathrm{CH}$ on the optical density of spore suspensions at $650 \mathrm{~nm}\left(\mathrm{OD}_{650}\right)$. Data represent the mean of four determinations, and error bars indicate the standard deviation of the mean. The same characters represent no significant difference $(p>0.05)$, and different characters represent a significant difference $(p<0.05)$ in Fisher's LSD among treated samples. 
FAEs with $G$. stearothermophilus because of their extremely high heat resistance.

The spore counts of $G$. stearothermophilus were substantially decreased by $\mathrm{CH}$ at $100^{\circ} \mathrm{C}$ for $60 \mathrm{~min}$ in the presence of $\mathrm{MC}_{10}$ or $\mathrm{MC}_{12}$ (Fig. 2). Significant inactivation caused by high temperatures and long treatment times indicates the important contribution of heat to the combined effect of $\mathrm{CH}$ with FAEs. Kato and Shibasaki (1975) revealed that $\mathrm{MC}_{10}$ and $\mathrm{MC}_{12}$ improve the inactivation effect of $\mathrm{HT}$ at $50^{\circ} \mathrm{C}$ for $5 \mathrm{~min}$ by about $3 \log \mathrm{CFU} / \mathrm{mL}$ on E. coli and Pseudomonas aeruginosa. Fujimoto et al. (2006) found that the combined use of FAEs and ultrahigh temperature (UHT; $125^{\circ} \mathrm{C}$, $10 \mathrm{~s}$ ) served as a substitute for conventional UHT treatment at a higher temperature $\left(135^{\circ} \mathrm{C}, 30 \mathrm{~s}\right)$ against $G$. stearothermophilus spores in chicken extract. On the other hand, while the combined effect of $\mathrm{CH}$ with FAEs was much more prominent after $\mathrm{CH}$ at $100^{\circ} \mathrm{C}$ for $60 \mathrm{~min}$, the effect was much decreased at milder heat conditions (Fig. 1, 2). Consistent with these results, we previously revealed that the combined effect of $\mathrm{CH}$ with FAEs was prominent only above $80^{\circ} \mathrm{C}$ on $B$. subtilis spores (Klangpetch et al., 2013). It has also been reported that carbonation treatment at $30 \mathrm{MPa}$ decreased spore counts of $G$. stearothermophilus drastically at $95^{\circ} \mathrm{C}$, although inactivation was not induced by temperatures between 35 to $85^{\circ} \mathrm{C}$ (Watanabe et al., 2003). These results indicate that there is a threshold of heat impact for each kind of spore, suggesting that heating above a certain threshold temperature with $\mathrm{CH}$ and FAEs could enhance the inactivation effect. Stecchini et al. (2006) suggested that the glassy state of the cortex could be associated with the heat resistance of spores. In that study, a reversible heat capacity shift ascribable to the transformation of cortex from a rigid, glass-like amorphous solid to a visco-elastic rubber glassy state was observed at $90-115^{\circ} \mathrm{C}$ with $B$. subtilis spores by differential scanning calorimetry. This result indicates that structural changes in the cortex may occur at $90-100^{\circ} \mathrm{C}$ in $G$. stearothermophilus spores, resulting in increased sensitivity to FAEs. Additionally, a prominent combined effect of $\mathrm{CH}$ upon longer treatment $(60 \mathrm{~min})$ indicates the importance of treatment time. Increased duration of $\mathrm{CH}$ treatment could also help improve the combined effect with FAEs on spores. However, to date there have been few studies on the effect of treatment time on spore inactivation.

The combined effect of $\mathrm{CH}$ with FAE against $G$. stearothermophilus spores was larger with $\mathrm{MC}_{10}$ than with $\mathrm{MC}_{12}$ (Fig. 2), although both $\mathrm{MC}_{10}$ and $\mathrm{MC}_{12}$ completely inhibited proliferation of $G$. stearothermophilus. These results are consistent with those reported earlier for B. subtilis spores (Klangpetch et al., 2013). The primary bacteriostatic effects of FAEs likely reflect the intensity of the combined effects with $\mathrm{CH}$, although conclusive proof will require detailed comparison of the bacteriostatic effect between $\mathrm{MC}_{10}$ and $\mathrm{MC}_{12}$ in $\mathrm{NB}$.

It is possible that pressurized $\mathrm{CO}_{2}$ enhanced the bacteriostatic effect of FAEs against spores. The decrease in $\mathrm{OD}_{650}$ of $G$. stearothermophilus spore suspensions after $\mathrm{CH}$ was significantly greater than after HT at the same temperature and for the same duration (Fig. 3). Therefore, $\mathrm{CH}$ could induce more spore germination than HT, thereby enhancing the bacteriostatic effect of FAEs against germinated spores and causing significant inactivation. It has been reported that spore germination is initiated by carbonation $\left(35^{\circ} \mathrm{C}, 6.5 \mathrm{MPa}, 30 \mathrm{~min}\right)$ despite almost no initiation of germination by hydrostatic pressure under the same conditions with B. coagulans (Furukawa et al., 2004). The authors described that carbonation might initiate spore germination due to lytic germination enzymes, which are known to be initiated by hydrostatic pressure; however, lytic enzymes could not contribute to carbonation-germination due to the low $\mathrm{pH}$ used during treatment. One explanation of the effect of $\mathrm{CH}$ on bacterial spores is that the protons generated during $\mathrm{CH}$ neutralize the negative charge on the cortex layer, inducing germination (Noma et al., 2011). Germinated spores might be more permeable to various substances, indicating the possibility that $\mathrm{CH}$-induced germination could contribute to the combined effect of $\mathrm{CH}$ with FAEs. Spore germination induced by $\mathrm{CH}$ could increase permeability towards FAEs. Additionally, $\mathrm{CH}$ was shown to increase the hydrophobicity of spores (Furukawa et al., 2006). $\mathrm{MC}_{10}$ and $\mathrm{MC}_{12}$ have a low hydrophile-lipophile balance of 6.5 and 5.3, respectively. Therefore, $\mathrm{CH}$ may enhance the adhesion of $\mathrm{MC}_{10}$ and $\mathrm{MC}_{12}$ to the spore surface. Another possibility is that the $\mathrm{CO}_{2}$ molecules saturating the spore suspension under pressure act as a carrier of FAEs to the spore surface. These possibilities lead to the consideration that the hydrophobicity of FAEs and of spore surface play a role in enhancing the combined effects of $\mathrm{CH}$ with FAEs.

\section{Conclusion}

Severe $\mathrm{CH}$ conditions are required $\left(95^{\circ} \mathrm{C}, 30 \mathrm{MPa}, 120 \mathrm{~min}\right)$ to inactivate one of the most heat resistant spores, $G$. stearothermophilus (Watanabe et al., 2003). In this study, the use of $\mathrm{MC}_{10}$ or $\mathrm{MC}_{12}$ reduced the required $\mathrm{CH}$ pressure and treatment time to $5 \mathrm{MPa}$ and $60 \mathrm{~min}$ at $100^{\circ} \mathrm{C}$. This result could help solve problems caused by the harsh conditions used to inactivate microorganisms in food, such as loss of food quality. For this approach to be put to practical use, further studies are needed to elucidate the mechanisms of spore inactivation by combined treatment with $\mathrm{CH}$ and FAEs.

Acknowledgements The authors would like to thank Taiyo Kagaku Co., Ltd., Mie, Japan, for kindly providing $\mathrm{MC}_{10}$ and $\mathrm{MC}_{12}$.

Part of this research was supported by the Towa Foundation for Food Research.

\section{References}

Dillow, A.K, Dehghani, F, Hrkach, J.S, Foster, N.R, and Langer R. (1999). Bacterial inactivation by using near- and supercritical carbon dioxide. Proc. Natl. Acad. Sci. USA. 96, 10344-10348. 
Feeherry, F.E., Munsey, D.T., and Rowley, D.B. (1987). Thermal Inactivation and injury of Bacillus stearothermophilus spores. Appl. Environ. Microbiol., 53, 365-370.

Fujimoto, A., Torii, K., Watanabe, M., and Miyamoto, T. (2006). Antimicrobial activities of fatty acid esters against $B$. stearothermophilus strains isolated from liquid seasoning. J. Antibact. Antifungal Agents., 34, 693-701.

Furukawa, S., Saita, K., Kato, T., Shimoda, M., and Hayakawa, I. (2000). Inactivation of Bacillus stearothermophilus and Bacillus coagulans spores as indicators of sterilization by reciprocal pressurization. J. Fac. Agric., Kyushu Univ., 45, 183-188.

Furukawa, S., Watanabe, T., Tai, T., Hirata, J., Narisawa, N., Kawarai, T., Ogihara, H., and Yamasaki, M. (2004) Effect of high pressure gaseous carbon dioxide on the germination of bacterial spores. Int. J. Food Microbiol., 91, 209-213

Furukawa, S., Watanabe, T., Koyama, T., Hirata, J., Narisawa, N., Ogihara, H., and Yamasaki, M. (2006). Effect of high pressure carbon dioxide on the clumping of the bacterial spores. Int. J. Food Microbiol., 106, 95-98.

Hong, S.-I. and Pyun, Y.-R. (1999). Inactivation kinetics of Lactobacillus plantarum by high pressure carbon dioxide. J. Food Sci., 64, 728-733.

Ishikawa, H., Shimoda, M., Tamaya, K., Yonekura, A., Kawano, T., and Osajima, Y. (1997) Inactivation of Bacillus spores by the supercritical carbon dioxide micro-bubble method. Biosci., Biotechnol., Biochem., 61, 1022-1023.

Kato, N. and Shibasaki, I. (1975). Comparison of Antimicrobial activities of fatty acids and their esters. J. Ferment. Technol., 53, 793-801. (In Japanese).

Kimsey, H.R., Adams, D.M., and Kabara, J.J. (1981). Increased inactivation of bacterial spores at high temperatures in the presence of monoglycerides. J. Food Saf., 3, 69-82.

Klangpetch, W., Nakai, T., Noma, S., Igura, N., and Shimoda, M. (2013). Combined effects of carbonation with heating and fatty acid esters on inactivation and growth inhibition of various Bacillus spores. J. Food. Prot., 76, 1575-1581

Nakayama, M., Fujimoto, A., Higuchi, A., Watanabe, M., Sadakari, K., Lio, M., and Miyamoto, T. (2003). Studies of growth characteristics of Bacillus strains isolated from a liquid seasoning. J. Jpn. Soc. Food Sci. Technol., 50, 537-545. (in Japanese)

Noma, S., Yamashita, N., Klangpetch, W., Igura, N., and Shimoda, M. (2011). Effects of carbonation with heating on germination of Bacillus subtilis spores. Food Sci. Technol. Res., 17, 523-527.

Patterson, M.F. and Kilpatrick, D.J. (1998). The combined effect of high hydrostatic pressure and mild heat on inactivation of pathogens in milk and poultry. J. Food Prot., 61, 432-436.

Shibasaki, I. (1979). Antimicrobial activity of fatty acids and their esters. Hakkokogaku kaishi., 57, 164-176. (In Japanese).

Spilimbergo, S. and Bertucco, A. (2003). Non-thermal bacteria inactivation with dense $\mathrm{CO}_{2}$ Biotechnol. Bioeng., 84, 627-638.

Stecchini, M.L., Del Torre, M., Venir, E., Morettin, A., Furlan, P., and Maltini, E. (2006). Glassy state in Bacillus subtilis spores analyzed by differential scanning calorimetry. Int. J. Food Microbiol., 106, 286-290.

Watanabe, T., Furukawa, S., Hirata, J., Koyama, T., Ogihara, H., and Yamasaki, M. (2003). Inactivation of Geobacillus stearothermophilus spores by high-pressure carbon dioxide treatment. Appl. Environ. Microbiol., 69, 7124-7129.

Wei, C.I., Balaban, M.O., and Fernand, S.Y. (1991). Bacterial effect of high pressure $\mathrm{CO}_{2}$ treatment on foods spiked with Listeria or Salmonella. J. Food. Prot., 54, 189-193 